\title{
A STUDY ON ACCEPTABILITY OF E-LEARNING IN INDIAN EDUCATIONAL INSTITUTIONS
}

\author{
GEORGE EASAW $^{1}$, MIHIR DASH ${ }^{*}$ \\ ${ }^{1}$ Area Chair, Operations Management, School of Business, Alliance University, Bangalore, India \\ ${ }^{2}$ Area Chair, General Management, School of Business, Alliance University, Bangalore, India \\ *Email: mihir@alliance.edu.in
}

Received: 30 May 2021, Revised and Accepted: 3 August 2021

\begin{abstract}
Though e-learning is broadly accepted across the education spectrum as an effective teaching-learning medium, its acceptance is found very wanting. This paper looks at the basic process of innovation that can induce teaching faculty in India to take up e-learning and to understand how innovative teaching-learning processes like e-learning can be applied to education. It goes on further to identify and understand some of the broadly accepted reasons for the low acceptability and usage with the help of an online survey. The survey was used to study what motivates the student and teacher to take e-learning as an effective pedagogy and to answer some of the pertinent problems relating to its low acceptability. The analysis of the survey results is given. A new "stakeholder involvement and feedback based" theoretical model is proposed explaining how to implement e-learning effectively in educational institutions in India. Some possible suggestions like effective problem-solving tools like Total Quality Management (TQM) to help overcome the drawbacks in the system are also proposed.
\end{abstract}

Keywords: E-learning, Emerging economies, Stakeholder involvement, Feedback-based e-learning model, Low acceptability.

(C) 2021 The Authors. Published by Innovare Academic Sciences Pvt Ltd. This is an open access article under the CC BY license (https://creativecommons.org/licenses/by/4.0/). DOI: https://dx.doi.org/10.22159/ijoe.2021v9i6.42813. Journal homepage: https://innovareacademics.in/journals/index.php/ijoe

\section{INTRODUCTION}

In the education delivery system, Information and Communication Technology (ICT) has grown in recent years as an efficient and effective means of disseminating information to aid in the teaching-learning process. Innovation is a necessary ingredient of the present-day offering to the student, mainly because it interests them to look for something new and creative in life. Innovation is defined as the creation and introduction of new products and services, strategies, systems, structures and processes that generate new sources of value and growth for an organization (O'Sullivan \& Dooley, 2009). The two vital points in innovation are to generate value for the organization to be shared by its customers and generate new avenues of growth for the organization. Both of these points are vital for the continued survival of the organization. Innovation is basically of two types: incremental and radical. Incremental innovation is the gradual and slow improvement of a product or process or strategies over existing ones making them better, faster, cheaper or more effective. This is also called "market pull" innovation. Radical innovation, on the other hand, happens with new technologies (such as the internet, air travel, email, and so on), new business models (such as Amazon, Flipkart, Alibaba, and so on) or breakthrough businesses (for example, Wal-Mart). This is also called "technology push" innovation (Tidd \& Bessant, 2009). When we look at innovation in education, we can look at how the stakeholders benefit. The stakeholders range from students, teaching staff, non-teaching staff, educational institute managements, parents, organizations that employ them, the regulator/government and the final benefactors/society. Any process which would help the student to be more effective in his learning process and to convert his learning and education gained from the education process to be used for raising the standard of living and wellness of the society and personal well-being would qualify to be an innovation. On the part of teaching, any process which would help the teaching and nonteaching staff to effectively deliver the content to the students that would be beneficial to them would qualify to be called an innovation. The Institution, in turn, provides the infrastructure for the students and the Instructors and non-teaching faculty to interact at a place and engage in knowledge delivery and sharing. Parents would naturally be concerned whether it is fair and value returns in the money being spent on the education of their wards. Employing organizations would look at how much value the educated students add to their process, which in turn helps the society by building wealth. The regulator, i.e. the government, would naturally be interested in knowing how the students and the educators are able to contribute the needed manpower in the country and solve unemployment for it to go along a pre-planned path of economic growth and development. Society would be looking at how can the educational institutions and the students together contribute and help build a better equitable dispensation that would raise the standard of living of the society. Given this scenario, let us try to understand the benefits of innovation in education, whether we need to innovate and if so, how to go about it. The delivery mechanism can influence the teaching-learning process. Using the modern advanced principles of ICT, if we can tide over the constraints of time and distance, enabling asynchronous learning to synchronous learning, the value addition to the end customer/student will be really great.

\section{REVIEW OF THE RELATED LITERATURE}

Technological advances that are changing the training and education domain have been studied by Rosett (2002). Elearning is defined as the use of computer network technology, primarily over an Intranet or over the internet, to deliver information and instruction to individuals (Welsh, Wanberg, Brown, \& Simmering, 2003). Computer-based learning, online learning, computer-assisted learning, distributed learning, and web-based learning are sometimes used to mean the same as elearning across organizations. E-learning can be described as any system that includes generates and disseminates information and is designed to improve performance (Rosenberg, 2001). Synchronous e-learning refers to learning where the learners are requested to be in front of their computers all the time, while asynchronous e-learning refers to learning that is pre-recorded or available to employees at any time of the day (Rosenberg, 2001). Blended learning is a blend or mix of technology and classroom delivery options and is a very popular method of e-learning content delivery. The 
authors are aware of some of the engineering colleges and business schools in India where e-learning is being used to a limited extent. Welsh et al. (2003) provide an extensive review of the developments in the e-learning domain. It has been found in their review by going through past research in the area of e-learning that firstly, learning can be effectively carried out by technologically delivered courses; secondly, technology does help to reduce costs if there are large number of learners, geographically dispersed with the courses being offered repeatedly. Thirdly, if the end-user perceives there is no benefit for him by the course, the completion rates are going to be very low. Fourthly, adults generally have positive attitudes towards technology-delivered classes. The Technology Acceptance Model (Davies, 1989) is an important model for analyzing the factors explaining acceptance of technological innovations on two fundamental constructs, perceived ease of use (PEOU) and perceived usefulness (PU), both in turn affected by external variables. The basic TAM has been extended as the Unified Theory of Acceptance and Use of Technology (UTAUT; Venkatesh, Morris, Davis, \& Davis, 2003), which found effort expectancy and performance expectancy as significant antecedents of the intention to use technological innovation, moderated by external factors, including demographics (gender, age, and experience), social influence, and voluntariness of use. Several studies have examined the factors affecting preference for e-learning. Bolliger and Martindale (2004) found that instructor availability and response time to questions have an impact on students' satisfaction with e-learning. Endres and Hurtubis (2009) found five factors determining student preference for e-learning: learning practices, course materials, faculty practices, studentto-student interaction, and online course tools. Comer, Lenaghan and Sengupta (2015) found that students had a greater preference for e-learning for qualitative courses over quantitative courses and for introductory-level courses over advanced courses.

\section{E-learning as an effective teaching-learning tool}

The present-day student doing graduate studies in college has to keep herself abreast of more facts and information than a graduate student maybe fifty years back. The sources of information and volume of knowledge were less then. Knowledge is doubling every eight years now. It may not be possible for students to keep pace with everything; instead, they will be looking at specializations and how to acquire the necessary skills for a particular specialization (Carroll, 2011). The two trends of 'rapid knowledge obsolescence and rapid knowledge emergence' are major threats faced by educational institutions. How to change their offerings to the student community depending on the needs of the society and specializations makes the education system all the more dynamic (Carroll, 2011). The job scenario also keeps changing with varying knowledge requirements. Jobs that were in demand some years back are ignored by society as needs have changed and new skills and job requirements have emerged. So this brings us to the needs of present-day education, to make it creative, up-to-date, easily accessible and available, and all the more interesting. Classroom pedagogy has existed for hundreds of years. With a burgeoning global population now hitting seven billion, and with China and India accounting for about two-fifths of humanity, it is all the more necessary that education should spread out to more and more people, thereby raising their skills, knowledge, earnings and standard of living. In India, the need is very acute. Out of the Indian population of 1.25 billion (as per 2011 census), the median age is 26.7 years meaning 610 million people are below the age of 26.7 years, i.e., a very youthful population. This has been otherwise called in literature as the demographic dividend (Aiyer \& Mody, 2011). The rates at which old jobs get obsolete and new skills get introduced should force the authorities to have a relook at the ways and means by which education is spread through the masses (Carroll, 2011). Conventional educational institutions have a limitation to the number of students who can enroll, facilities that can be provided and the subjects that can be taught. On the other hand, by e-learning, more students can be reached in different geographies, at their convenient times, with diverse and interesting subjects. E-learning has been in use as an offshoot of ICT. It is an incremental innovation achieved through a radical introduction of technology (Salmon, 2000). The old process of learning from classrooms and institutions has been moved over to cyberspace. Any person desirous of learning can now access these e-learning sites and acquire information and knowledge. Looking from this perspective, we find, e-learning is a service to the community that generates a new source of value for the customer, i.e., the student and helps in the growth of the organization offering the course by offering more and more courses and enabling more and more students to join the course from all distant corners of the globe. The value being offered to the customer is manifold: value from the convenience, reach, time, distance, variety, course material, choosing the professor and pedagogy perspective While it offers great convenience in terms of being accessible any time of the day from anywhere on planet earth with access to the internet, the plethora of courses offered, the varying types of course material, videos, audios, hand-outs, notes, discussion forums, chat sessions for clarification and discussions between participants and with faculty members, the ease with which the best professors on a topic can be made to teach a particular subject to a worldwide audience with lecture sessions, or discussions, case sessions pedagogical style makes e-learning a highly sought after pedagogy in the modern-day.

\section{Impact of plagiarism on e-Learning}

According to the office of Community Standards of Stanford University (n.d.), plagiarism is defined as the use, without giving reasonable and appropriate credit to or acknowledging the author or source, of another person's original work, whether such work is made up of code, formulas, ideas, language, research, strategies, writing or other form(s). Office of the Dean of College at Princeton University (2020) has defined plagiarism as the deliberate use of "someone else's language, ideas, or another original (not common-knowledge) material without acknowledging its source. Plagiarism is an important threat to scientific, researched and original publishing as it results in stealing somebody else's original thoughts, ideas, research, works or writing and claiming it to be one's own without acknowledging the true source. In India, the rampant incidence of plagiarism is observed in report preparation by students from professional and arts and science colleges for their statement of work done after a period of research in industry or the field. There are reasons why this happens in India. Firstly, the Indian academic circles have not come heavily as a community in preventing this. The second reason is that there is yet to be any recognition of personal knowledge as opposed to community knowledge, which has been in the Indian community for centuries. Universities and educational institutions, in their own way, work to prevent plagiarism. Because of the ease of cut, copy and paste from different sources on the internet while submitting assignments, this study also looks at how students and faculty look at plagiarism.

\section{Change management}

Change management is an approach to transitioning individuals, teams, and organizations to a desired future state. Out of fear of having to learn new technologies and committing mistakes and being ridiculed upon, faculty hesitate to take up new technology areas. A thought is proposed whether a shortterm course on Change Management would be helpful in faculty members taking up to e-learning after overcoming all fears.

\section{OBJECTIVE}

The objective of the study was to find out why e-learning is not popular with the teaching faculty in technical and management institutions in India.

\section{METHODOLOGY}

The study was conducted via an online survey using a structured questionnaire. The data for the study was collected 
from a sample of fifty-five respondents. The majority of the respondents $(77.4 \%)$ were postgraduate. Further, a minority of the respondents (18.2\%) had used e-learning for less than three months; the majority (61.8\%) had used e-learning for less than one year and most (72.7\%) had used e-learning for less than two years. The dependent variables for the study included the perception of e-learning generating interest, the perception that synchronous learning was more effective than asynchronous learning, and the willingness to recommend elearning to friends and students. The independent variables for the study included location factors (i.e., where the e-learning was being accessed), helpfulness factors (i.e., for what types of content they perceived that e-learning would be helpful), preference factors (i.e., for what types of content they preferred e-learning), and purpose factors (i.e., why they were using e-learning). Two control dummy variables were also considered: postgraduate (i.e., whether the respondent was postgraduate or not) and used more than one year (i.e., whether the respondent had used e-learning for more than one year or not). These factors corresponded with the construct of perceived usefulness and its antecedents in the TAM and UTAUT. The analysis was performed for each of the dependent variables and each of the factors separately using dummy variable regressions of the form

$$
y=a_{1} D_{1}+a_{2} D_{2}+b_{1} F_{1}+\cdots+b_{k} F_{k}
$$

Where $D_{1}$ and $D_{2}$ represent the control dummy variables, and $F_{1}, \ldots F_{k}$ represent the dummy variables for each of the levels of the factors. Note that the constant term was dropped, as respondents could choose multiple levels of each of the factors.

\section{RESULTS AND DISCUSSION}

The location of usage/access of e-learning by the respondents varied considerably. The most frequent usage was in educational institutions (66.7\%), followed by from home (35.2\%), at professional institutions (25.9\%), and other locations such as cyber cafes, wi-fi hotspots, and so on (11.1\%). This reflects the increasing popularity of e-learning in educational institutions and the convenience e-learning offers for home study. However, there is a scope for expanding the presence of e-learning in professional institutions in India.

The respondents found e-learning to be helpful primarily for qualitative topics $(87.3 \%)$, followed by quantitative topics $(60.0 \%)$, practical topics $(40.0 \%)$, and others $(10.9 \%)$. In line with this, the respondents preferred e-learning primarily for qualitative topics $(76.4 \%)$, followed by quantitative topics (54.6\%), practical topics $(49.1 \%)$, and others $(7.3 \%)$. In particular, there was found to be a significant tendency not to prefer e-learning for qualitative topics even among respondents who found e-learning to be helpful $(z=-2.45, p=$ $0.014)$. This suggests that synchronous learning may be preferred for qualitative topics over asynchronous learning. On the other hand, there was a tendency for respondents to prefer e-learning for practical topics even though they may not have found it to be helpful. This highlights the usage of online videos and animations in supporting learning for practical topics. The primary purposes for using e-learning were to improve the effectiveness of learning $(60.0 \%)$, to try innovative technologies $(54.6 \%)$, due to lack of time $(27.3 \%)$, and due to lack of resources $(23.6 \%)$. The primary uses of e-learning by the respondents were in demonstrating videos $(71.7 \%)$, giving hand-outs/notices $(50.0 \%)$, administering exams $(41.3 \%)$ paper valuation $(26.1 \%)$, preparing teaching plans $(23.9 \%)$ final assessment (13.0\%), and administering time-bound equizzes (4.4\%). This again highlights the role of e-learning in improving the delivery of content and enhancing the teachinglearning process. Most of the respondents (54.5\%) perceived that it was not necessary to provide support for students for effectively using e-learning, while $9.1 \%$ and $36.4 \%$ of the respondents perceived that partial and extensive support, respectively, should be provided for the students. The modern generation of students is very well-versed with the nuances of state-of-art technology, so there may not be any need for support in this area. The usage of e-learning in a class by trainers was high, with $19.5 \%$ and $65.9 \%$ of them using elearning partially and extensively, respectively, in class, and only $14.6 \%$ of them not using e-learning in class. Further, $16.0 \%$ and $78.0 \%$ of them were willing to adopt e-learning partially and extensively, respectively, if supported by a change management programme. However, only $47.0 \%$ of the respondents were aware of the Massive Open Online Courses (MOOCs) offered on different topics by very popular sites such as www.coursera.org, www.edX.org, www.udacity.com. Change management is especially needed for the more senior faculty, who are generally averse to the extensive usage of modern ICT in teaching. The respondents highly perceived that e-learning helped generate interest in the subject as compared to classroom teaching (mean 3.60, std. dev. 1.18), but that synchronous learning as in classrooms was more effective than asynchronous learning as in e-learning (mean 3.42, std. dev. 1.02). The respondents were highly willing to recommend elearning to their friends/students (mean 8.11, std. dev. 1.97). This also points to the growing popularity of e-learning among teachers and students.

The impact of locational factors on the perception of e-learning generating interest is presented in table 1.

Table 1: Impact of locational factors on the perception of e-learning generating interest

\begin{tabular}{|l|c|c|c|c|}
\hline \multicolumn{1}{|c|}{ Location factors } & Coeff. & SE & Beta & P-value \\
\hline Postgraduate & 1.244 & 0.522 & 0.288 & 2.384 \\
\hline Used more than one year & 0.602 & 0.478 & 0.096 & 1.258 \\
\hline Educational institution & 1.620 & 0.466 & 0.346 & 3.478 \\
\hline Professional institution & 1.274 & 0.526 & 0.175 & 2.420 \\
\hline From home & 1.197 & 0.435 & 0.191 & 2.750 \\
\hline Other & 1.468 & 0.747 & 0.132 & 0.0100 \\
\hline
\end{tabular}

Dependent variable: e-learning helps generate interest in the subject as compared to classroom teaching

The locational factors were found to have a significant influence on the perception of e-learning generating interest $\left(\mathrm{R}^{2}=83.1 \%, \mathrm{~F}=37.826, \mathrm{p}=0.0000\right)$. Access from educational institutions had the strongest influence on the perception of elearning generating interest, followed by access from home, access from professional institutions, and lastly, access from other locations. Also, these factors had a significantly higher influence for postgraduates than for undergraduates.

The impact of helpfulness factors on the perception of elearning generating interest is presented in table 2 .

Table 2: Impact of helpfulness factors on the perception of e-learning generating interest

\begin{tabular}{|l|c|c|c|c|c|}
\hline \multicolumn{1}{|c|}{ Helpfulness factors } & Coeff. & SE & Beta & t Stat & P-value \\
\hline Postgraduate & 0.536 & 0.481 & 0.124 & 1.114 & 0.1855 \\
\hline Used more than one year & 0.812 & 0.416 & 0.131 & 1.954 & 0.0285 \\
\hline Helpful for quantitative & 0.678 & 0.428 & 0.138 & 1.581 & 0.0600 \\
\hline Helpful for qualitative & 2.159 & 0.462 & 0.527 & 4.668 & 0.0000 \\
\hline
\end{tabular}


Innovare Journal of Education, Vol 9, Issue 6, 2021, 16-23

\begin{tabular}{|l|c|c|c|c|}
\hline \multicolumn{1}{|c|}{ Helpfulness factors } & Coeff. & SE & Beta & t Stat \\
\hline Helpful for practical & 0.838 & 0.416 & 0.142 & 2.013 \\
\hline Helpful for others & 0.531 & 0.639 & 0.047 & 0.0250 \\
\hline
\end{tabular}

Dependent variable: e-learning helps generate interest in the subject as compared to classroom teaching

The helpfulness factors were found to have a significant influence on the perception of e-learning generating interest $\left(\mathrm{R}^{2}=87.4 \%, \mathrm{~F}=54.163, \mathrm{p}=0.0000\right)$. Helpfulness in qualitative topics had the strongest influence on the perception of e-learning generating interest, followed by access from helpfulness in practical topics, while other factors were not significant. Also, these factors had a significantly higher influence for users who used e-learning for more than one year than for those who used e-learning for less than one year.

The impact of preference factors on the perception of elearning generating interest is presented in table 3 .

Table 3: Impact of preference factors on the perception of e-learning generating interest

\begin{tabular}{|l|c|c|c|c|}
\hline \multicolumn{1}{|c|}{ Preference factors } & Coeff. & SE & Beta & t Stat \\
\hline Postgraduate & 0.759 & 0.538 & 0.175 & 1.410 \\
\hline Used more than one year & 0.886 & 0.438 & 0.143 & 0.0825 \\
\hline Prefer for quantitative & 1.179 & 0.434 & 0.229 & 2.024 \\
\hline Prefer for qualitative & 1.518 & 0.465 & 0.346 & 3.26245 \\
\hline Prefer for practical & 1.226 & 0.458 & 0.225 & 2.677 \\
\hline Prefer for others & 0.219 & 0.874 & 0.016 & 0.0010 \\
\hline
\end{tabular}

Dependent variable: e-learning helps generate interest in the subject as compared to classroom teaching

The preference factors were found to have a significant influence on the perception of e-learning generating interest $\left(\mathrm{R}^{2}=85.8 \%, \mathrm{~F}=47.354, \mathrm{p}=0.0000\right)$. Preference for qualitative topics had the strongest influence on the perception of elearning generating interest, followed by a preference for quantitative topics, and a preference for practical topics, while other factors were not significant. Also, these factors had a significantly higher influence for users who used e-learning for more than one year than for those who used e-learning for less than one year.

The impact of purpose factors on the perception of e-learning generating interest is presented in table 4 .

Table 4: Impact of purpose factors on the perception of e-learning generating interest

\begin{tabular}{|l|c|c|c|c|}
\hline \multicolumn{1}{|c|}{ Purpose factors } & Coeff. & SE & Beta & P-value \\
\hline Postgraduate & 1.250 & 0.431 & 0.288 & 2.898 \\
\hline Used more than one year & 0.414 & 0.445 & 0.067 & 0.0030 \\
\hline Lack of time & 1.078 & 0.571 & 0.145 & 0.929 \\
\hline Lack of resources & 0.049 & 0.541 & 0.006 & 0.0987 \\
\hline Innovative technology & 0.900 & 0.411 & 0.172 & 0.0325 \\
\hline To improve effectiveness of learning & 2.351 & 0.389 & 0.479 & 2.188 \\
\hline
\end{tabular}

Dependent variable: e-learning helps generate interest in the subject as compared to classroom teaching

The purpose factors were found to have a significant influence on the perception of e-learning generating interest $\left(\mathrm{R}^{2}=86.7 \%, \mathrm{~F}=51.233, \mathrm{p}=0.0000\right)$. Usage to improve the effectiveness of learning had the strongest influence on the perception of e-learning generating interest, followed by usage of innovative technology and lack of time, while other factors were not significant. Also, these factors had a significantly higher influence on postgraduates than undergraduates.

The impact of locational factors on the perception of synchronous learning is more effective than asynchronous learning is presented in table 5 .

Table 5: Impact of locational factors on the perception of synchronous learning is more effective than asynchronous learning

\begin{tabular}{|c|c|c|c|c|c|}
\hline Location factors & Coeff. & SE & Beta & t Stat & P-value \\
\hline Postgraduate & 1.652 & 0.589 & 0.409 & 2.805 & 0.0040 \\
\hline Used more than one year & 0.630 & 0.582 & 0.101 & 1.082 & 0.1425 \\
\hline Educational institution & 1.432 & 0.526 & 0.331 & 2.722 & 0.0045 \\
\hline Professional institution & 0.508 & 0.595 & 0.076 & 0.853 & 0.1990 \\
\hline From home & 0.721 & 0.504 & 0.123 & 1.431 & 0.0800 \\
\hline Other & 0.173 & 0.895 & 0.016 & 0.194 & 0.4235 \\
\hline
\end{tabular}

Dependent variable: synchronous learning as in classrooms is more effective than asynchronous learning as in e-learning

The locational factors were found to have a significant influence on the perception of synchronous learning is more effective than asynchronous learning $\left(\mathrm{R}^{2}=76.5 \%, \mathrm{~F}=23.373, \mathrm{p}\right.$ $=0.0000)$. Access from educational institutions had the strongest influence on the perception of synchronous learning being more effective than asynchronous learning, while other factors were not significant. Also, these factors had a significantly higher influence on postgraduates than undergraduates.

The impact of helpfulness factors on the perception of synchronous learning is more effective than asynchronous learning is presented in table 6.

Table 6: Impact of helpfulness factors on the perception of synchronous learning being more effective than asynchronous learning

\begin{tabular}{|l|c|c|c|c|c|}
\hline \multicolumn{1}{|c|}{ Helpfulness factors } & Coeff. & SE & Beta & t Stat & P-value \\
\hline Postgraduate & 0.310 & 0.467 & 0.077 & 0.665 & 0.2545 \\
\hline Used more than one year & 0.777 & 0.415 & 0.128 & 1.872 & 0.0340 \\
\hline Helpful for quantitative & 0.294 & 0.411 & 0.066 & 0.715 & 0.2390 \\
\hline
\end{tabular}


Innovare Journal of Education, Vol 9, Issue 6, 2021, 16-23

\begin{tabular}{|l|c|c|c|c|}
\hline \multicolumn{1}{|c|}{ Helpfulness factors } & Coeff. & SE & Beta & t Stat \\
\hline Helpful for qualitative & 2.743 & 0.447 & 0.734 & 6.137 \\
\hline Helpful for practical & 0.002 & 0.411 & 0.000 & 0.0000 \\
\hline Helpful for others & 0.160 & 0.607 & 0.016 & 0.4980 \\
\hline
\end{tabular}

Dependent variable: synchronous learning as in classrooms is more effective than asynchronous learning as in e-learning

The helpfulness factors were found to have a significant influence on the perception that synchronous learning is more effective than asynchronous learning $\left(\mathrm{R}^{2}=87.2 \%, \mathrm{~F}=49.806, \mathrm{p}\right.$ $=0.0000$ ). Helpfulness in qualitative topics had the strongest influence on the perception of synchronous learning being more effective than asynchronous learning, while other factors were not significant. Also, these factors had a significantly higher influence for users who used e-learning for more than one year than for those who used e-learning for less than one year.

The impact of preference factors on the perception of synchronous learning is more effective than asynchronous learning is presented in table 7.

Table 7: Impact of preference factors on the perception of synchronous learning being more effective than asynchronous learning

\begin{tabular}{|l|c|c|c|c|}
\hline \multicolumn{1}{|c|}{ Preference factors } & Coeff. & SE & Beta & P-value Stat \\
\hline Postgraduate & 0.936 & 0.575 & 0.233 & 1.629 \\
\hline Used more than one year & 0.971 & 0.479 & 0.160 & 2.027 \\
\hline Prefer for quantitative & 0.263 & 0.468 & 0.055 & 0.0295 \\
\hline Prefer for qualitative & 2.164 & 0.488 & 0.539 & 0.561 \\
\hline Prefer for practical & 0.270 & 0.492 & 0.052 & 0.2885 \\
\hline Prefer for others & 0.289 & 0.911 & 0.023 & 0.548 \\
\hline
\end{tabular}

Dependent variable: synchronous learning as in classrooms is more effective than asynchronous learning as in e-learning

The preference factors were found to have a significant influence on the perception that synchronous learning is more effective than asynchronous learning $\left(\mathrm{R}^{2}=82.9 \%, \mathrm{~F}=35.638, \mathrm{p}\right.$ $=0.0000$ ). Preference for qualitative topics had the strongest influence on the perception of synchronous learning being more effective than asynchronous learning, while other factors were not significant. Also, these factors had a significantly higher influence for users who used e-learning for more than one year than for those who used e-learning for less than one year. The impact of purpose factors on the perception of synchronous learning is more effective than asynchronous learning is presented in table 8.

Table 8: Impact of purpose factors on the perception of synchronous learning being more effective than asynchronous learning

\begin{tabular}{|l|c|c|c|c|}
\hline \multicolumn{1}{|c|}{ Purpose factors } & Coeff. & SE & Beta & t Stat \\
\hline Postgraduate & 1.157 & 0.484 & 0.288 & 2.391 \\
\hline Used more than one year & 0.226 & 0.523 & 0.037 & 0.0105 \\
\hline Lack of time & 0.938 & 0.673 & 0.140 & 0.432 \\
\hline Lack of resources & -0.008 & 0.631 & -0.001 & -0.393 \\
\hline Innovative technology & 1.111 & 0.444 & 0.226 & 0.0850 \\
\hline To improve effectiveness of learning & 1.913 & 0.465 & 0.425 & 0.4950 \\
\hline
\end{tabular}

Dependent variable: synchronous learning as in classrooms is more effective than asynchronous learning as in e-learning

The purpose factors were found to have a significant influence on the perception that synchronous learning is more effective than asynchronous learning $\left(\mathrm{R}^{2}=82.5 \%, \mathrm{~F}=34.497, \mathrm{p}=\right.$ $0.0000)$. Usage to improve the effectiveness of learning had the strongest influence on the perception of synchronous learning being more effective than asynchronous learning, followed by usage of innovative technology, while other factors were not significant. Also, these factors had a significantly higher influence on postgraduates than undergraduates.

The impact of locational factors on the willingness to recommend e-learning to friends and students is presented in table 9.

Table 9: Impact of locational factors on the willingness to recommend e-learning to friends and students

\begin{tabular}{|l|c|c|c|c|}
\hline \multicolumn{1}{|c|}{ Location factors } & Coeff. & SE & Beta & P-value \\
\hline Postgraduate & 2.942 & 1.083 & 0.309 & 2.716 \\
\hline Used more than one year & 1.124 & 1.020 & 0.080 & 0.0045 \\
\hline Educational institution & 3.392 & 0.978 & 0.332 & 3.102 \\
\hline Professional institution & 2.576 & 1.093 & 0.162 & 3.470 \\
\hline From home & 3.336 & 0.908 & 0.244 & 2.356 \\
\hline Other & 2.548 & 1.664 & 0.0005 & 3.675 \\
\hline
\end{tabular}

Dependent variable: recommend e-learning to friends/students

The locational factors were found to have a significant influence on the willingness to recommend e-learning to friends and students $\left(\mathrm{R}^{2}=85.1 \%, \mathrm{~F}=42.960, \mathrm{p}=0.0000\right)$. Access from educational institutions had the strongest influence on the willingness to recommend e-learning to friends and students, followed by access from home, access from professional institutions and lastly, access from other locations. Also, these factors had a significantly higher influence on postgraduates than undergraduates.

The impact of helpfulness factors on the willingness to recommend e-learning to friends and students is presented in table 10 .

Table 10: Impact of helpfulness factors on the willingness to recommend e-learning to friends and students

\begin{tabular}{|l|c|c|c|c|c|}
\hline \multicolumn{1}{|c|}{ Helpfulness factors } & Coeff. & SE & Beta & t Stat & P-value \\
\hline Postgraduate & 0.965 & 0.938 & 0.101 & 1.029 & 0.1545 \\
\hline Used more than one year & 1.673 & 0.828 & 0.121 & 2.021 & 0.0295 \\
\hline
\end{tabular}


Innovare Journal of Education, Vol 9, Issue 6, 2021, 16-23

\begin{tabular}{|l|c|c|c|c|c|}
\hline \multicolumn{1}{|c|}{ Helpfulness factors } & Coeff. & SE & Beta & P-value \\
\hline Helpful for quantitative & 0.942 & 0.847 & 0.088 & 1.112 & 0.1360 \\
\hline Helpful for qualitative & 5.428 & 0.907 & 0.603 & 5.983 \\
\hline Helpful for practical & 1.899 & 0.817 & 0.148 & 2.323 \\
\hline Helpful for others & 1.514 & 1.246 & 0.061 & 0.0125 \\
\hline
\end{tabular}

Dependent variable: recommend e-learning to friends/students

The helpfulness factors were found to have a significant influence on the willingness to recommend e-learning to friends and students $\left(\mathrm{R}^{2}=90.1 \%, \mathrm{~F}=69.469, \mathrm{p}=0.0000\right)$. Helpfulness in qualitative topics had the strongest influence on the willingness to recommend e-learning to friends and students, followed by access from helpfulness in practical topics, while other factors were not significant. Also, these factors had a significantly higher influence for users who used e-learning for more than one year than for those who used e-learning for less than one year.

The impact of preference factors on the willingness to recommend e-learning to friends and students is presented in table 11.

Table 11: Impact of preference factors on the willingness to recommend e-learning to friends and students

\begin{tabular}{|l|c|c|c|c|c|}
\hline \multicolumn{1}{|c|}{ Preference factors } & Coeff. & SE & Beta & t Stat & P-value \\
\hline Postgraduate & 1.646 & 1.124 & 0.173 & 1.465 \\
\hline Used more than one year & 2.039 & 0.926 & 0.147 & 2.201 \\
\hline Prefer for quantitative & 2.213 & 0.920 & 0.198 & 2.406 & 0.0165 \\
\hline Prefer for qualitative & 3.676 & 0.982 & 0.380 & 3.744 & 0.0100 \\
\hline Prefer for practical & 2.889 & 0.963 & 0.239 & 3.000 \\
\hline Prefer for others & -0.143 & 1.820 & -0.005 & -0.079 & 0.0020 \\
\hline
\end{tabular}

Dependent variable: recommend e-learning to friends/students

The preference factors were found to have a significant influence on the willingness to recommend e-learning to friends and students $\left(\mathrm{R}^{2}=87.2 \%, \mathrm{~F}=52.407, \mathrm{p}=0.0000\right)$. Preference for qualitative topics had the strongest influence on the willingness to recommend e-learning to friends and students, followed by a preference for practical topics, and a preference for quantitative topics, while other factors were not significant. Also, these factors had a significantly higher influence for users who used e-learning for more than one year than for those who used e-learning for less than one year.

The impact of purpose factors on the willingness to recommend e-learning to friends and students is presented in table 12.

Table 12: Impact of purpose factors on the willingness to recommend e-learning to friends and students

\begin{tabular}{|l|c|c|c|c|}
\hline \multicolumn{1}{|c|}{ Purpose factors } & Coeff. & SE & Beta & P-value \\
\hline Postgraduate & 3.188 & 1.016 & 0.334 & 3.136 \\
\hline Used more than one year & 0.659 & 1.062 & 0.048 & 0.0015 \\
\hline Lack of time & 2.611 & 1.352 & 0.162 & 1.931 \\
\hline Lack of resources & -0.288 & 1.264 & -0.017 & -0.228 \\
\hline Innovative technology & 2.422 & 0.964 & 0.209 & 2.513 \\
\hline To improve effectiveness of learning & 4.297 & 0.930 & 0.4105 & 0.00300 \\
\hline
\end{tabular}

Dependent variable: recommend e-learning to friends/students

The purpose factors were found to have a significant influence on the willingness to recommend e-learning to friends and students $\left(\mathrm{R}^{2}=85.0 \%, \mathrm{~F}=43.457, \mathrm{p}=0.0000\right)$. Usage to improve the effectiveness of learning had the strongest influence on the willingness to recommend e-learning to friends and students, followed by usage of innovative technology and lack of time, while other factors were not significant. Also, these factors had a significantly higher influence on postgraduates than undergraduates. The results of the study suggest some similarities and differences with the literature. The control variables of 'postgraduate' and 'used more than one year,' which roughly correspond with the experience construct in the UTAUT, were found to have a significant positive impact on the dependent variables, as was found by Venkatesh et al. (2003). This suggests that e-learning may be more suitable for postgraduate studies than for undergraduate studies, perhaps reflecting their greater maturity. Also, helpfulness and preference for qualitative topics were found to have a significant positive impact on the dependent variables, roughly corresponding to the findings of Comer et al. (2015), that students had a greater preference for e-learning for qualitative courses over quantitative courses. Finally, the purpose factors of 'lack of time,' 'innovative technology,' and 'improve the effectiveness of learning' were found to have a significant positive impact on the dependent variables. The last aspect, in particular, is specific to e-learning, in that 'improved effectiveness of learning' itself becomes a driver for increased usage of e-learning. Thus, increasing the effectiveness of e-learning would reinforce the perceived usefulness of e-learning, leading to increasing its adoption.
A model for e-learning implementationBased on the results as given above and the personal experience of the authors in the e-learning domain, stakeholder involvement and a feedback-based theoretical model is proposed that can help in the implementation of e-learning in educational institutes in India. The model works on the premise that commitment from the top management ${ }^{1}$ is necessary for the success of any elearning project. Taking the stakeholders to confidence regarding the new learning methodology, the security of the job and a promise to return to conventional blackboard teaching in case the approach fails are necessary for its success. The first step of any e-learning implementation will be to ensure top management commitment. The concerns related to the intellectual property rights of the notes and presentations hosted at the e-learning site have to be ensured by the management. They need to give an assurance that the notes and presentations prepared by the faculty are not misused by others and will not be copied without the permission of the author. By protecting the intellectual property rights of the faculty member, it should be possible to get the confidence of the faculty members to give their best to contribute still better and improve the offering to the students. The technical support in terms of content generation by subject experts and the hardware and software support by software programmers and hardware engineers is the next important step. Content generation is one of the most difficult steps in e-learning. The

\footnotetext{
1 Top Management commitment, protection of IP rights and adequate compensation to content generating faculty members points emerged after collecting feedback and consultation with the participants.
} 
subject expert is involved in the content generation, though the data entry may be done by others. A constant check on the quality of content and the ease with which it loads at the user end machine is needed. An important step is the systems analysis step which highlights the possible up-gradation needed for the hardware and software configuration of the elearning setup. Delivery and feedback is the final stage, where the actual delivery of the course to learners either in the classrooms or at distant places is made possible. Any e-learning setup should have a feedback loop from the users to the subject expert and hardware/software programmers to be in place. This will ensure the system is up-to-date and effective in achieving its objectives. Occasional monthly meetings between the content generator (subject expert) and hardware-software programmers and representatives of top management are advisable to keep track of whether the system is able to meet the necessary goals for which it has been put in place.

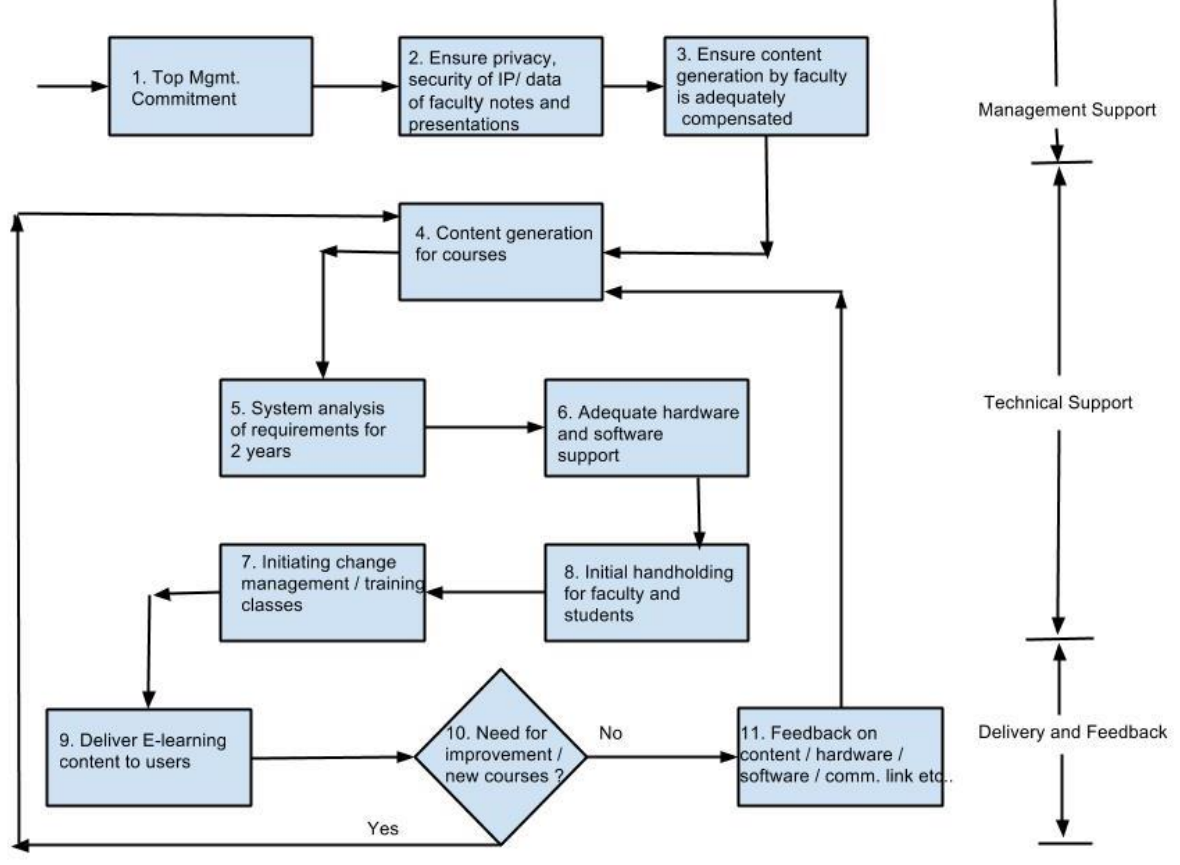

Fig. 1: Theoretical model for e-learning implementation

Incorporating Total Quality Management (TQM)

Very frequently, it is found that the feedback reported from students, faculty and other users of the e-learning site has problems relating to slow speed, could be either a communication link, Internet bandwidth, number of users, or RAM problem. The uniqueness of this model would be a problem-solving approach in the feedback/ improvement loop using the Ishikawa Cause and Effect diagram (to list out all causes leading to a deterioration in service of the E-learning site) and the Pareto Chart (to find out the relative frequency of the problems occurring at the site, to classify the frequently occurring problems according to their frequency and to attend to the higher frequency problems first). This approach is found to reduce the recurrence of technical problems than software issues or training-related problems.

\section{CONCLUSION}

The users/beneficiaries accept that e-learning is a very innovative learning method where technology and ICT are used in the teaching-learning process facilitating asynchronous learning. $48.5 \%$ of users prefer classroom teaching to elearning, as it is perceived to be more efficient. Understanding the particular demographics of the country (with its rich demographic dividend favoring the country), finding new resources to aid in the education of a large mass of youngsters in the country is still the greatest challenge facing the policy makers of this country. The main finding from this study is that blended learning (complementing classroom teaching with elearning) is what interests the student community in India. Further, e-learning was found to be more suitable for postgraduate students than for undergraduate students. The other interesting finding from this study has been that elearning is a very effective aid in improving the teachinglearning process. The asynchronous learning possible with this mode, breaking the barriers of space and time is indeed very impactful. The potential benefits and disadvantages of blended learning need to be further studied. As much as it benefits the students, the benefits to the teaching faculty are manifold like in test administration, valuation and final assessment.

Scope for further research

The present research had limitations in that the same questionnaire was given to both the user, i.e. faculty member and the beneficiary, i.e. the student. The particular age group of the respondent, his geographical area of the world, his basic background training were not noted down. Extension work could focus on separate questionnaires for user and beneficiary besides noting down the additional details as noted above. Though the survey respondents have come from across the world, mainly being former professional colleagues and former students of the authors, engineering and management professionals (particularly who have all been educated in India and presently some continue their working life outside India), the sample is claimed to be a truly representative sample of the e-learning community across the country. A wider sample could be taken of respondents from other developing and emerging economies of Asia and Africa to get a deeper insight into the issue of low acceptability.

\section{ACKNOWLEDGEMENT}

We would like to thank several of our colleagues and students for their valuable suggestions in preparing our manuscript.

\section{AUTHORS CONTRIBUTIONS}

The first author was responsible for conceptualizing the study, collecting the data, and writing the paper. The second author was responsible for data analysis and interpretation. 


\section{CONFLICT OF INTEREST}

The authors declare no conflict of interest.

\section{FUNDING SOURCE}

The authors declare no specific funding source (personal funds).

\section{REFERENCES}

- Bolliger, D. U., \& Martindale, T. (2004). Key factors for determining student satisfaction in online courses. International Journal on E-learning, 3(1), 61-67. Retrieved from https://www.learntechlib.org/primary/p/2226/

- Carroll, J. (2011). Trend: The Future of Knowledge..... and the Era of Fast Knowledge Obsolescence! Retrieved from https://jimcarroll.com/2011/10/trend-the-future-ofknowledge/

- Comer, D. R., Lenaghan, J. A., \& Sengupta, K. (2015). Factors that affect students' capacity to fulfill the role of online learner. Journal of Education for Business, 90(3), 145-55. Retrieved from https://eric.ed.gov/?id=EJ1054751

- Davies, F. D. (1989). Perceived usefulness, perceived ease of use, and user acceptance of information technology. MIS Quarterly, 13(3), 319-340. doi:10.2307/249008

- $\quad$ Endres, M. L., Hurtubis, C. A., Chowdhury, S., \& Frye, C. (2009). The multifaceted nature of online mba student satisfaction and impacts on behavioral intentions. Journal of Education for Business, 84(5), 304-12. doi:10.3200/JOEB.84.5.304-312

- Mody, A. \& Aiyer, S. (2011). The demographic dividend: Evidence from the Indian States. Retrieved from https://www.imf.org/en/Publications/WP/Issues/2016/
12/31/The-Demographic-Dividend-Evidence-from-theIndian-States-24660

- O'Sullivan, D. \& Dooley, L. (2009). Applying Innovation. Thousand Oaks, CA: SAGE Publications.

- Office of the Dean of College at Princeton University. (2020). Academic integrity at Princeton. Retrieved from https://odoc.princeton.edu/sites/odoc/files/Academic\% 20Integrity\%20Booklet\%202020-21.pdf

- Rosenberg, M. J. (2001). E-learning, strategies for delivering knowledge in the digital age. New York: McGraw Hill.

- $\quad$ Rosett, A. (2002). Waking in the night and thinking about E-learning. In A. Rosset (Ed.), ASTD E-learning Handbook. New York: McGraw Hill.

- Salmon, G. (2000). E-moderating: The key to teaching and learning online. London: Kogan Page.

- $\quad$ Stanford Office of Community Standards Student Affairs. (n.d.). What is plagiarism? Retrieved from https://communitystandards.stanford.edu/policies-andguidance/what-

plagiarism\#: :text=\%22\%20For\%20purposes $\% 20$ of $\% 2$ 0the $\% 20$ Stanford,research $\% 2$ C\%20strategies $\% 2 \mathrm{C} \% 20 \mathrm{w}$ riting\%20or\%20other

- Tidd, J., \& Bessant, J. (2009). Managing Innovation, Integrating Technological, Market and Organizational Change (4e). New Delhi: Wiley India.

- Venkatesh, V., Morris, M. G., Davis, F. D., \& Davis, G.B. (2003). User acceptance of information technology: Toward a unified view. MIS Quarterly, 27, 425-478. doi: $10.2307 / 30036540$

- Welsh, E. T., Wanberg, C. R., Brown, K. G., \& Simmering, M. J. (2003). E-learning: Emerging uses, empirical results and future directions. International Journal of Training and Development, $\quad 7(4), \quad 245-258 . \quad$ doi:10.1046/j.13603736.2003.00184.x 